\title{
Facebow is a Valuable Tool in Prosthodontics That Facilitates an Articulator to Closely Simulate Jaw Movements
}

Pravinkumar G Patil

International Journal of Prosthodontics and Restorative Dentistry (2019): 10.5005/jp-journals-10019-1255

A facebow, as well described in the glossary of prosthodontic terms (GPT), ${ }^{1}$ is an instrument used to record the spatial relationship of the maxillary arch to some anatomic reference point or points and then transfer this relationship to an articulator; it orients the dental cast in the same relationship to the opening axis of the articulator; customarily, the anatomic references are the mandibular transverse horizontal axis and one other selected anterior reference point. The purpose of the facebow is to orient the maxillary cast to the condyles of the articulator in defined positions. ${ }^{2}$ In recent years, the literature indicated few controversial statements regarding the utility of the traditional facebow in prosthodontic and restorative practice. Farias-Neto ${ }^{3}$ has done a systematic review in 2013 on eight randomized controlled trials (all were related to complete dentures and occlusal splints) and suggested that the facebow transfer is not imperative to achieve better clinical results in prosthodontics. The authors also stated that no clinical study has investigated its use in fixed and removable partial dentures. The Journal of American Dental Association (JADA) has published an interesting article in 2016 by Yohn ${ }^{4}$ who has reviewed 13 studies and 1 internet video to claim a strong evidence to support the irrelevancy of the facebow transfer. The findings indicated that the facebow has nothing to do with speech, the fit and comfort of the prostheses, facial contours, the color of the teeth and their arrangement, chewing efficiency, and the psychological aspects of the treatment. However, Nagy, and Goldstein ${ }^{5}$ in 2019 suggested that the traditional facebow still has practicality in a modern restorative practice, even though digital alternatives have been proposed and hold promise for the future.

With this background, I look back on my prosthodontic practice and trying to understand the relevance of the Facebow transfer. The process of the facebow transfer facilitates mounting of a maxillary cast that ultimately "fixes the occlusal plane" onto the articulator so that the opening-closing arc of the articulator remains almost same as that of the opening-closing arc of the mandible of the patient in a three-dimensional special relationship. This means the facebow enables an articular to move or simulate (or I would rather say "behave") according to movements of the mandible of the patient in eccentric motions. With this "behavior of the articulator," technician develops the occlusal morphology or cuspal inclinations in eccentric motions so that there will be minimal range of adjustments required during prosthesis issue appointment. This is important especially in fixed (tooth- or implant-supported) restorations, as excessive trimming (chairside) during occlusal adjustments may
Department of Prosthodontics, Division of Clinical Dentistry, School of Dentistry, International Medical University, Kuala Lumpur, Malaysia Corresponding Author: Pravinkumar G Patil, Department of Prosthodontics, Division of Clinical Dentistry, School of Dentistry, International Medical University, Kuala Lumpur, Malaysia, Phone: +60 1135022042, e-mail: pravinandsmita@yahoo.co.in

How to cite this article: Patil PG. Facebow is a Valuable Tool in Prosthodontics That Facilitates an Articulator to Closely Simulate Jaw Movements. Int J Prosthodont Restor Dent 2019;9(4):107.

Source of support: Nil

Conflict of interest: None

expose the underlying metal or zirconia coping/substructure. Such chairside adjustments also require additional steps to polish or glaze the surface-porcelain of the fixed restorations. The quality of the restoration may be compromised due to exposure of the metal/zirconia coping or thin remaining restoration thickness or perforation of the crown. Such complications are inevitable if the occlusal morphology of the prosthesis has not been developed on the articulator that "does not behave" like a patient meaning that "does not receive Facebow transfer." The complete denture occlusion may not be so critical, rightly pointed out by few authors, ${ }^{3}$ as the acrylic teeth can be trimmed easily to refine occlusion without the risk of metal exposure or crown perforation and additionally mucosal resiliency allows denture/s to get adjusted easily by the patient. Hence, there is a need of further studies to support the relevance of the facebow especially in a fixed prosthodontic practice including implant restorations.

\section{References}

1. The glossary of prosthodontic terms. J Prosthet Dent 2017;117(5S): e1-e105. DOI: 10.1016/j.prosdent.2016.12.001.

2. Christiansen RL. Rationale of the face-bow in maxillary cast mounting. J Prosthet Dent 1959;9(3):388-398. DOI: 10.1016/0022-3913(59) 90069-1.

3. Farias-Neto A, Dias AH, de Miranda BF, et al. Face-bow transfer in prosthodontics: a systematic review of the literature. J Oral Rehabil 2013;40(9):686-692. DOI: 10.1111/joor.12081.

4. Yohn K. The face bow is irrelevant for making prostheses and planning orthognathic surgery. J Am Dent Assoc 2016;147(6):421-426. DOI: 10.1016/j.adaj.2015.12.011.

5. Nagy WW, Goldstein GR. Facebow use in clinical prosthodontic practice. J Prosthodont 2019;28(7):772-774. DOI: 10.1111/jopr.12944.

o The Author(s). 2019 Open Access This article is distributed under the terms of the Creative Commons Attribution 4.0 International License (https://creativecommons. org/licenses/by-nc/4.0/), which permits unrestricted use, distribution, and non-commercial reproduction in any medium, provided you give appropriate credit to the original author(s) and the source, provide a link to the Creative Commons license, and indicate if changes were made. The Creative Commons Public Domain Dedication waiver (http://creativecommons.org/publicdomain/zero/1.0/) applies to the data made available in this article, unless otherwise stated. 